\title{
Characterization and Adhesion Strength of Porous Electrosprayed Polymer-Hydroxyapatite Composite Coatings
}

\author{
T. Sopcak ${ }^{1,2 *}$, L. Medvecky ${ }^{2}$, T. Zagyva ${ }^{1}$, M. Dzupon ${ }^{2}$, J. Balko², K. Balázsi ${ }^{1}$ and C. Balázsi ${ }^{1}$ \\ ${ }^{1}$ Institute of Technical Physics and Materials Sciences, Centre for Energy Research, Hungarian Academy of Sciences, \\ Konkoly-Thege Miklós str. 29-33, 1121 Budapest, Hungary \\ ${ }^{2}$ Institute of Materials Research of SAS, Watsonova 47, 04001 Kosice, Slovak Republic
}

Received: 02 February 2018; accepted: 22 February 2018

\begin{abstract}
The current study was initiated in order to evaluate the adhesion strength of thin and porous hydroxyapatite (Hap) coatings on titanium (Ti) substrates deposited by the low temperature electrospraying method. The nanocrystalline hydroxyapatite powder was synthesized by coprecipitation method using eggshell biowaste as a nontoxic and natural source of the calcium precursor. Five hydroxyapatite coatings were electrosprayed onto Ti substrates by varying the concentration (0.05 and $0.1 \mathrm{wt} \%$ ) of polyethylene glycol (PEG) and polyvinylpyrrolidone (PVP) polymers in Hap suspensions. It has been shown that the adhesion strength of composite polymer-Hap coatings increased with increasing polymer concentration and the highest value $(8.75 \pm 0.75 \mathrm{MPa})$ was measured for the sample containing $0.1 \mathrm{wt} \%$ of PVP. The reason for the change in bonding strength was ascribed owing to microstructural changes caused by polymer addition whereas on one hand lower adhesion strength in Hap-0.1PEG was caused by the presence of separated polymer contained islands, and hence, weaker adhesion to substrate was found in this sample. On the other hand, more uniform, homogeneous, and denser microstructure resulted in an increasing cohesive strength inside the Hap-0.1PVP layer which lead to stronger mechanical bonding at the coating-substrate interface.
\end{abstract}

Keywords: Electrostatic spray deposition, coating, adhesion properties, titanium

\section{Introduction}

Titanium (Ti) and its alloys belong to a group of bioinert materials which are intended to be used in several clinical applications, especially for orthopedic and dental implants $[1,2]$. However, as in the case of other metallic prostheses, they exhibit poor capability to bond to living tissue which resulted in low fixation and formation of fibrous layer at the bone-implant interface [3]. Therefore, it is a great challenge to improve the bioactivity of the implant surface in order to enhance the osseointegration with bone tissue.

Hydroxyapatite, the most stable calcium phosphate $(\mathrm{CaP})$ member, has been widely used in various biomedical fields owing to its close chemical compositional similarity with natural bone [4]. The classical methods for Hap preparation include wet chemical processes as well as solid state procedure using precursors either of synthetic and biological nature [5-8]. However, Hap in pure form has poor mechanical properties; therefore, its using is restricted only for nonloadbearing application or as coatings of metallic implants [9]. The Hap coating on material surfaces creates a bioactive film which allows a direct bonding to the living bone and retaining high mechanical properties of $\mathrm{Ti}$ implants [10]. Moreover, the Hap-coated Ti promoted higher osteoblastic differentiation and proliferation as compared with uncoated Ti implants, thus enabling higher efficiency to enhance osteogenesis [11].

The adhesive strength between Hap coating and substrate is found as the most important characteristic which determines the quality of the applied coating and its clinical application [12]. The bonding strength of hydroxyapatite and metal substrate depends on various factors such as surface chemistry, microstructure, surface roughness of the substrate, and processing parameters of applied technique [12]. It has been shown that the adhesion strength between the Hap layer and metallic substrate is relatively poor which can lead to coating delamination at the coating-substrate interface [13]. Although sintering during the thermal plasma spraying (TPS) process

\footnotetext{
* Author for correspondence: tsopcak@saske.sk
}

improves the coating adhesion, high temperature results to decomposition of Hap to various phases such as alpha or beta tricalcium phosphates $(\alpha, \beta-\mathrm{TCP})$ having higher in vitro dissolution and resorption rates $[14,15]$. On the other hand, the addition of hydrophilic polymers to Hap, e.g., polyethylene glycol or polyvinyl alcohol, not only enhanced the adhesion to substrate but also retains high biocompatibility and bioactivity of the Hap coating $[16,17]$. The PEG-modified hydroxyapatite composite coating exhibited improved binding strength of Hap to the substrate with increased packing density of Hap particles without the need of sintering [16].

In fact, contrary to plasma spraying, the electrostatic spray deposition (ESD) represents a low temperature coating technique which allows the incorporation organic species, e.g., polymers or drugs during deposition process [18]. Depending on process condition, a wide variety of particles morphology in the form of thin nanometer range films can be deposited on the substrate surface [19]. Generally, ESD is a solvent-based method which involves electrostatic atomization of solution droplets containing dispersed particles which are sprayed onto grounded substrate under influence of high electrical forces. Subsequently, a thin film is formed, resulting from the evaporation of solvent during flight of droplets towards the substrate. Leeuwenburgh et al. $[20,21]$ in his pioneering works successfully deposited $\mathrm{CaP}$ coatings with defined chemical and morphological characteristics at different deposition condition. It was found that by changing processing parameters, e.g., chemical composition and mixing characteristic of precursor liquids, deposition temperature, needle to substrate distance, liquid flow rate, applied voltage etc. can significantly affect the initial droplet sizes and precipitation kinetics of the $\mathrm{CaP}$ solute and thus the quality, morphology, and thickness of the deposited coatings.

Hence, the purpose of this work was to evaluate the effect of polyethylene glycol and polyvinylpyrrolidone polymers addition on microstructural and adhesion strength changes of Hap coatings deposited on commercial Ti substrates. Adhesion strength of coated samples was tested by the standard tensile adhesion test ISO 13779-4. 


\section{Materials and Methods}

2.1 Substrate Preparation. Commercially pure Ti alloy (Ti$6 \mathrm{Al}-4 \mathrm{~V}$ discs with diameter of $35 \mathrm{~mm}$; thickness of $2 \mathrm{~mm}$; sandblasted with corundum particles [A12O3], $60 \mu \mathrm{m}$ [180 grit] in size, purchased from PROTETIM Kft., Hungary) were used as a substrate material. Before deposition, all substrates were ultrasonically cleaned in ethanol for $20 \mathrm{~min}$.

2.2 Preparation of Nanosized Hap Powder and Suspension. The nanosized Hap powder was synthesized by the precipitation of $0.2 \mathrm{M}$ of eggshell and $0.2 \mathrm{M}$ of $\left(\mathrm{NH}_{4}\right)_{2} \mathrm{HPO}_{4}$ (analytical grade, Merck, Darmstadt, Germany) solutions with the $\mathrm{Ca}-\mathrm{P}$ molar ratio of 1.66. The eggshell solution (calcium precursor prepared by dissolution of calcined eggshells in $\mathrm{HNO}_{3}$ [1:1]) was drop-wise added $(3 \mathrm{~mL} / \mathrm{min})$ to the phosphate solution at room temperature and $\mathrm{pH} 10.0$. The reaction mixture was vigorously stirred $(500 \mathrm{rpm})$, while the $\mathrm{pH}$ was maintained by the ammonia solution (reagent grade, $28 \mathrm{wt} \%$, Sigma-Aldrich). The obtained precipitate was aged for 4 days, washed with deionized water and ethanol, filtered over the membrane filter (Millipore, $0.2 \mu \mathrm{m}$ pore size), microwave dried (30 $\mathrm{min})$, and lyophilized (ilShin) for $5 \mathrm{~h}$. The as-prepared powder was dried in oven at $100{ }^{\circ} \mathrm{C}$ for another $1 \mathrm{~h}$.

The Hap suspensions for electrospaying were prepared as follows: $0.5 \mathrm{~g}$ Hap was dispersed in $100 \mathrm{~mL}$ of ethanol under vigorous mixing $(30 \mathrm{~min})$ and ultrasonication $(30 \mathrm{~min})$. The Hap-PEG and Hap-PVP suspensions were obtained after dissolving $0.05 \mathrm{~g}$ and $0.1 \mathrm{~g}$ of PEG (pellets; molecular weight [MW], 6000; Acros Organics) and PVP (powder; MW, $\sim 1,300,000$; Sigma-Aldrich) in ethanol and admixing $0.5 \mathrm{~g}$ of Hap powder into solutions. Suspensions were left for $30 \mathrm{~min}$ before ESD.

2.3 Electrostatic Spray Deposition of Coatings. Hap coatings were deposited using a commercially available ESD device (Ne100, Turkey) under room temperature at standardized conditions; fixed nozzle-substrate distance of $10.5 \mathrm{~cm}$, liquid flow rate of $3 \mathrm{~mL} / \mathrm{h}$, applied voltage of $13-14.5 \mathrm{kV}$, and spraying time of $45 \mathrm{~min}$ for each suspension, respectively. The ESD procedure started with filling the syringe by liquid and pumping through nozzle $(d=0.950 \mathrm{~mm})$. Charged droplets generated by the electrical forces were targeted onto the grounded substrate forming a thin layer on it after solvent evaporation. After deposition of coatings, the substrates were dried at room temperature in desiccator for $24 \mathrm{~h}$.

2.4 Characterization Methods. The surface morphology and thickness of the deposited coatings were assessed by scanning electron microscopy (SEM; LEO $1540 \mathrm{XB}, 2 \mathrm{kV}$ ). The average surface roughness $\left(R_{\mathrm{a}}\right)$ of the pure and coated Ti substrates was studied using confocal microscope (Sensofar Neox Plu). The phase composition of coatings was analyzed by X-ray diffraction analysis (XRD, Philips $\mathrm{X}^{\prime}$ PertPro, $\mathrm{Cu} \mathrm{K} \alpha$ radiation; $40 \mathrm{kV}, 50 \mathrm{~mA}, 2 \theta$ between $10^{\circ}$ and $60^{\circ}$ ) and Fourier transform infrared (FTIR) spectroscopy (FTIR Shimadzu IRAffinity1, $300 \mathrm{mg} \mathrm{KBr}+1 \mathrm{mg}$ sample) after scraping a desired amount of coatings from the substrate surfaces. The adhesion strength of deposited coatings was evaluated by the standard adhesion test ISO 13779-4 using bonding of substrate with the epoxy structural adhesive (3M, Scotch-Weld DP 460). After curing (24 h, room temperature), the adhesive strengths of glued components were measured on the tensile testing machine (Instron 5985, USA tensile load at a constant cross-head velocity $1 \mathrm{~mm} / \mathrm{min}$ ) until complete separation of coatings was recorded. The texture of detached coatings was analyzed by the SEM-energy dispersive X-ray (EDX) study. The testing procedure was repeated 3 times for each specimen, and the results were expressed as the average loads \pm standard deviation.

\section{Results}

3.1 Characterization of Hap Coatings. The average surface roughnesses $\left(R_{\mathrm{a}}\right)$ of the native Ti substrate and substrates after coating are illustrated in Table 1 . The close $R_{\mathrm{a}}$ values of the uncoated $(1.81 \pm 0.03)$ and Hap-coated $(1.88 \pm 0.05)$ Ti were measured. The roughness of coatings on Ti exhibited enhanced rise after applying of PEG- and PVP-doped Hap suspensions with $R_{\mathrm{a}}$ equal to $2.37 \pm 0.07$ and $2.10 \pm 0.06$ for Hap-0.1PEG and Hap-0.1PVP, respectively.

Figure 1 shows the surface morphology of Ti substrates observed by SEM. The strongly disrupted surface texture with irregular craters or holes with size up to $40 \mu \mathrm{m}$ was visible on uncoated Ti (Figure 1a, b) due to surface deformation after sandblasting process. Electrosprayed Hap coating without polymer additives (Figure 1c, d) was characterized by spongy-like morphology with large fraction of spherical micropores up to $10 \mu \mathrm{m}$ size. From more detailed cross-sectioned view resulted the formation of very fine porosity (nanometric pore size) across the layer and coating thickness was approximately $4 \mu \mathrm{m}$. The coating was composed of spherical Hap agglomerates with size that did not exceed $2 \mu \mathrm{m}$. The addition of only 0.05 and $0.1 \mathrm{wt} \%$ PEG into the Hap-ethanol suspension (Figure 1e, $\mathrm{f}$ and $\mathrm{g}, \mathrm{h}$ ) resulted in some surface compaction with partial non-uniform filling of larger Hap pores (about $10 \mu \mathrm{m}$ ) by PEG, which create elevated islands on coatings, despite that the formation of rougher coatings with average thickness of $\sim 2$ and $3 \mu \mathrm{m}$ for Hap-0.05PEG and Hap-0.1PEG, respectively, was demonstrated. On the other hand, absolutely different surface texture was found on the Ti samples coated with the Hap-0.05PVP and Hap-0.1PVP suspensions (Figure 1i, $\mathrm{j}$ and $\mathrm{k}, \mathrm{l}$ ) where smoother and denser layers were clearly seen on $\mathrm{Ti}$ substrates and the origin micropores between the Hap particles were almost completely filled by PVP polymer. The detailed focused ion beam (FIB) cross-sectional images revealed comparable coating thickness of $\sim 2.0$ and $2.2 \mu \mathrm{m}$ for Hap-0.05PVP and Hap-0.1PVP samples, respectively.

The XRD analysis results (Figure 2) of scraped coatings did not show any significant changes in XRD patterns, and the main diffraction lines in all samples are attributed to the nanocrystalline hydroxyapatite (JCPDS 24-0033) with traces of PEG observed at $2 \theta=19.2^{\circ}$ and $23.4^{\circ}$ for Hap-0.05PEG and Hap-0.1PEG samples, respectively.

Similarly, the FTIR spectra of all coatings (Figure 3) revealed absorption bands typical for the nanocrystalline hydroxyapatite. Briefly, broad bands observed at $3560 / \mathrm{cm}$ and at $1640 / \mathrm{cm}$ can be attributed to the stretching vibrations of $\mathrm{OH}$ groups and bending vibration of $\mathrm{H}_{2} \mathrm{O}$, respectively [22]. The presence of peaks at 1460,1425 , and $875 / \mathrm{cm}$ was due to the $\left(v_{3}\right)$ and $\left(v_{2}\right)$ vibrations of carbonate groups in AB-hydroxyapatite [23]. Furthermore, the absorption bands observed at 1094, 1032, and $962 / \mathrm{cm}$ can be ascribed to the antisymmetric $\left(v_{3}\right)$ and symmetric $\left(v_{1}\right)$ stretching vibrations of $\mathrm{PO}_{4}^{3-}$ hydroxyapatite group, so as the doublet located around 603 and $564 / \mathrm{cm}$ is characteristic for the $\left(v_{4}\right)$ antisymmetric $\mathrm{P}-\mathrm{O}$ bending vibrations [24]. Besides this, in the spectra of the Hap samples containing PVP and PEG, the $\mathrm{CH}$ stretching vibrations at $\sim 2922$ and $2890 / \mathrm{cm}$ can be clearly identified in both type of coatings along with the weaker bands from $\mathrm{CH}$ bending $(1343 / \mathrm{cm})$ and $\mathrm{C}-\mathrm{N}$ stretching $(1289 / \mathrm{cm})$ vibrations

Table 1. Surface roughness of the coatings

\begin{tabular}{lc}
\hline Sample & Surface roughness, $R_{\mathrm{a}}(\mu \mathrm{m})$ \\
\hline Uncoated substrate & $1.81 \pm 0.02$ \\
Hap pure & $1.88 \pm 0.05$ \\
Hap-0.05PVP & $1.90 \pm 0.07$ \\
Hap-0.1PVP & $2.10 \pm 0.06$ \\
Hap-0.05PEG & $1.97 \pm 0.10$ \\
Hap-0.1PEG & $2.37 \pm 0.07$ \\
\hline
\end{tabular}



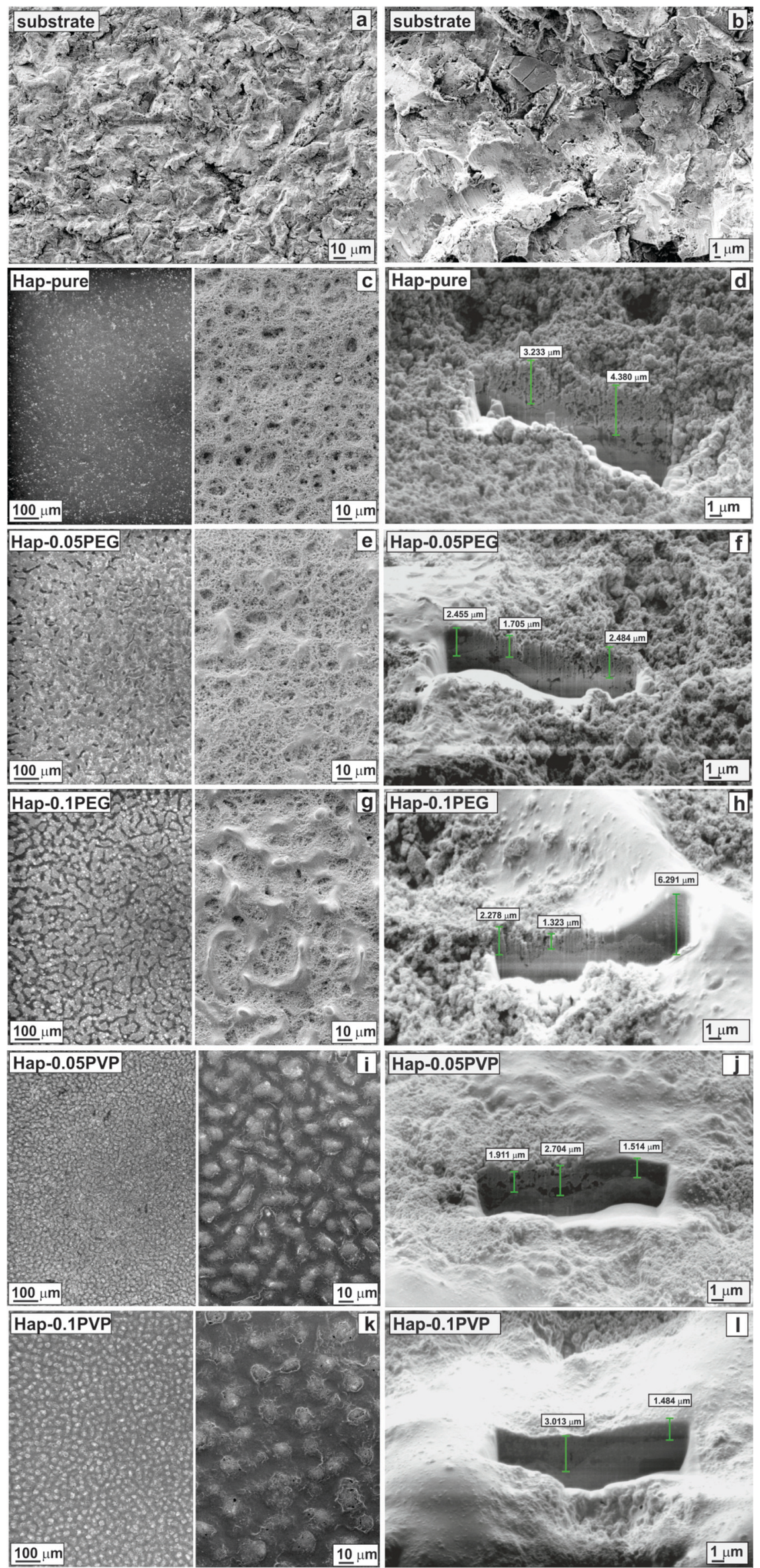

Figure 1. Surface morphology of pure Ti $(\mathrm{a}, \mathrm{b})$ and elecstrosprayed coatings on Ti substrates $(\mathrm{c}, \mathrm{d}-\mathrm{Hap}$; e, f - Hap $-0.05 \mathrm{PEG}$; g, h - Hap-0.1PEG; $\mathrm{i}, \mathrm{j}$ - Hap-0.05PVP; k, 1 - Hap-0.1PVP) 


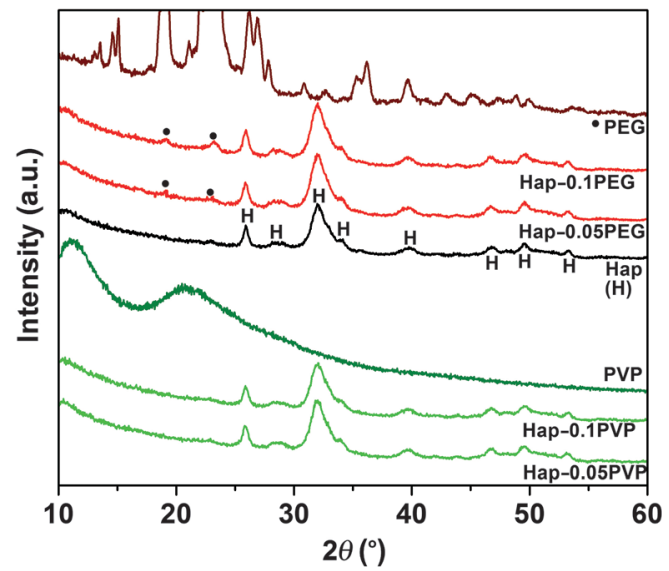

Figure 2. XRD analysis results of scraped coatings

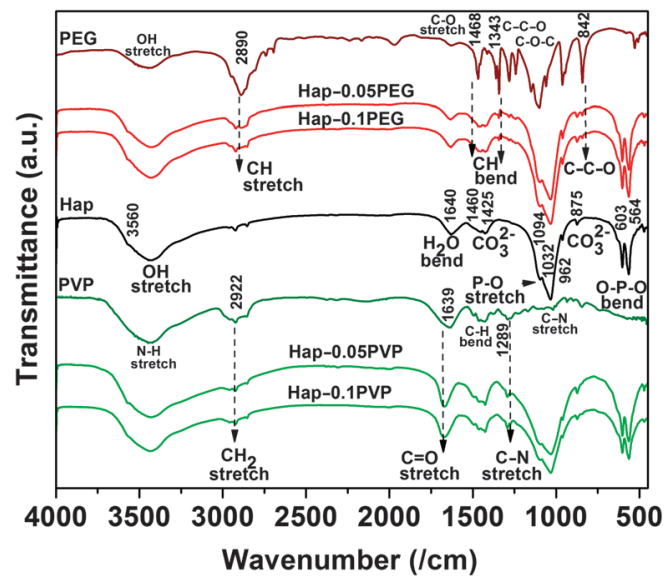

Figure 3. FTIR analysis results of scraped coatings

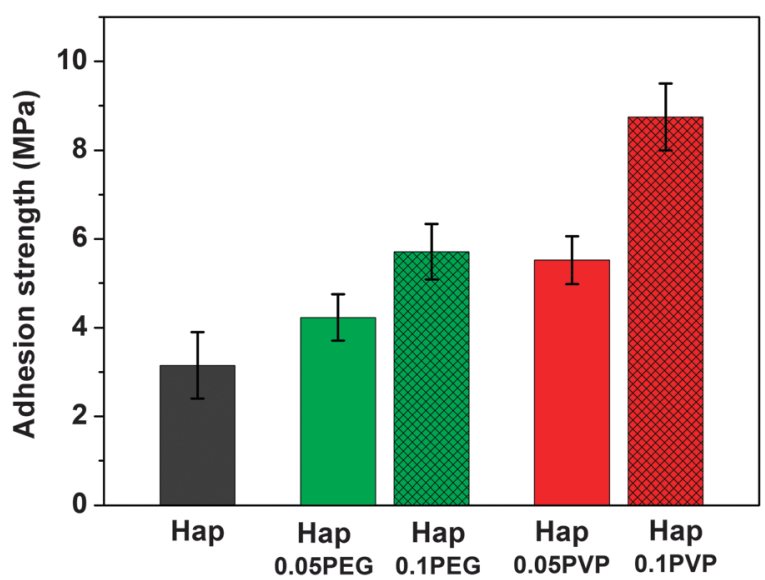

Figure 4. Variations of the tensile adhesive strengths for the coated samples for Hap-PEG and Hap-PVP samples, respectively [25, 26]. Moreover, the addition of PEG into Hap suspension revealed a new vibration of $\mathrm{C}-\mathrm{C}-\mathrm{O}$ bands [27] at around $840 / \mathrm{cm}$ arise from PEG, while in the case of PVP doped layers, the strong peaks at $1639 / \mathrm{cm}$ which are overlapping with the $\mathrm{H}_{2} \mathrm{O}$ bending vibrations can be attributed to the stretching vibration of $\mathrm{C}=\mathrm{O}$ groups in PVP [26].

3.2 Adhesion Strength of Hap Coatings. Figure 4 depicts the variations of the tensile adhesive strengths for the coated samples. The results showed the lowest adhesive strength of pure Hap coating on the Ti substrate $(3.15 \pm 0.75 \mathrm{MPa})$. As further shown, the adhesive strength of composite coatings increased gradually with the addition of polymers (PEG or PVP). While the Hap-0.05PEG- and Hap-0.05PVP-coated samples exhibited adhesive strengths of $4.23 \pm 0.52 \mathrm{MPa}$ and $5.52 \pm 0.75 \mathrm{MPa}$, almost double rise up to $8.75 \pm 0.75 \mathrm{MPa}$ and about $25 \%$ increase $(5.71 \pm 0.63 \mathrm{MPa})$ in bonding strength were measured for the Hap-0.1PVP and Hap-0.1PEG samples, respectively.

\section{Discussion}

Although many techniques have been used for producing Hap layers on metallic surfaces, plasma spraying is still the only capable method of creating coatings suitable for use in biomedical applications. In the current work, we tested the adhesion strength of Hap coatings prepared by electrospraying (Figure 5), which is in many ways much simpler and easier controllable deposition method in comparison with thermal spraying. By the ESD technique, thin and uniform $\mathrm{CaP}$ layers with different structure and morphology can be successfully deposited onto metallic substrates; however, there are still problems concerning with poor coating adhesion and the choice of adequate method for testing the adhesion properties of deposited layers. de Jonge et al. [28] tested the mechanical performance of the electrosprayed nanoscale collagen-calcium phosphate coatings on titanium substrate using the standardized tape test (ASTM D-3359) in order to determine the coating retention. However, the results obtained by this method might be discutable by taking into account the fact that the substrate surfaces were not completely covered by the coating layer.

In general, the adhesion between coating and substrate can be a result of both mechanical interlocking and chemical bonding [12]. The typical adhesion failure mode after the tensile strength test (ISO 13779-4) is composed of the combination of (co) cohesive (inside the coating layers) and (ad) adhesion (coating to substrate) failures at coating-substrate interfaces. In addition, if the bonding between the glue and uppermost coating layer is poor, adhesive failure takes place [29]. Previous studies have shown that there are many variables influencing the adhesive strength of plasma-sprayed Hap coatings [30, 31]. Yang et al. [30] evaluated the effect of coating characteristics, e.g., different microstructures, concentrations of impurity phases, and indices of crystallinity, on the mechanical strengths properties of the plasma-sprayed Hapcoated $\mathrm{Ti}$ implans. The results showed that the microstructure was the key factor influencing the mechanical stability of the Hap coating both in vitro and in vivo. Some related research

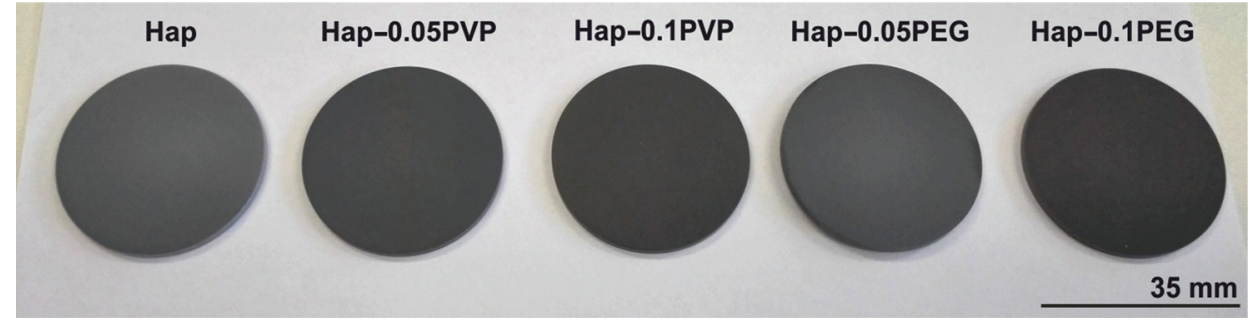

Figure 5. Illustration of coated samples 
investigated the influence of coating thickness on the bonding strength of Hap-coated Ti samples [31]. Earlier studies showed that thinner coatings with an average thickness of $\sim 50 \mu \mathrm{m}$ revealed higher adhesion strength in comparison with the $\sim 200 \mu \mathrm{m}$ Hap implants. However, in some cases, an abnormal increase in adhesion strength $(50-60 \mathrm{MPa})$ indicated that the measured data represent the strength of glue rather than the true bonding strength of the coating [32, 33].

In this work, from the fractographic analysis results of the detached layers from substrate after testing (Figure 6), it is evident that the glue penetrated in a large area inside the pure Hap layer (darker area) and enhanced the adhesion strength of coating due to both improving cohesion between Hap particles by glue and direct adhesion of glue or Hap-glue mixture to substrate. In this case, the measured adhesive strength of Hap coating was overestimated. Contrary to the above, detaching the composite polymer-Hap coatings (illustrated only for samples containing $0.1 \mathrm{wt} \%$ polymers) are characterized by the typical mixed adhesion-cohesion failure mode (Figure 7). The revealed lower bonding strength $(5.71 \pm 0.63 \mathrm{MPa})$ of the Hap-0.1PEG sample was probably because of weaker adhesion to substrate (more than $80 \%$ of tested coating surface detached continuously) and also because of being partially affected with stronger adhered areas (black regions) due to improved adherence or glue penetration across the layer via cracks or that pores cannot be omitted in explanation. On the other hand, despite comparable thickness and surface roughness of both composite coatings, the reason for the rapid increase in adhesion strength of the Hap-0.1PVP sample $(8.75 \pm 0.75 \mathrm{MPa})$ can be attributed to more uniform, homogeneous, and denser microstructure where the origin pores between the Hap particles were almost completely filed by PVP polymer, contrary to separated
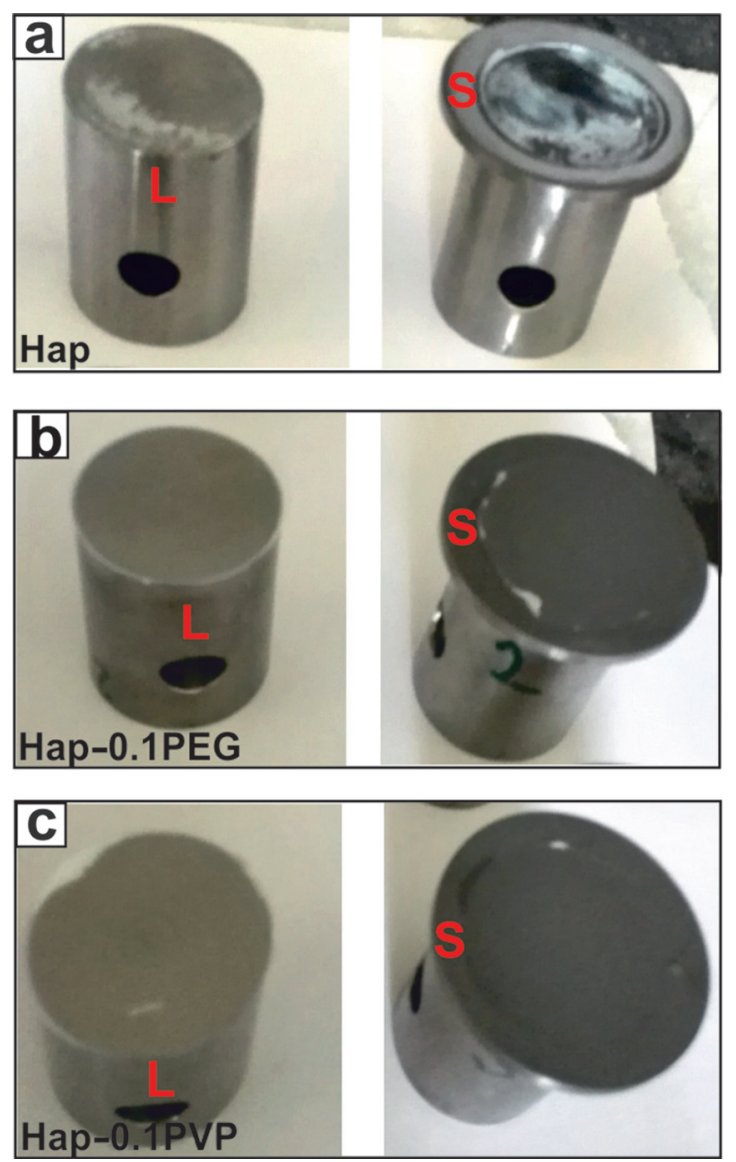

Figure 6. Schematic representation of samples after adhesion strength tests ( $\mathrm{L}$ - loading roots; $\mathrm{S}$ - substrate)
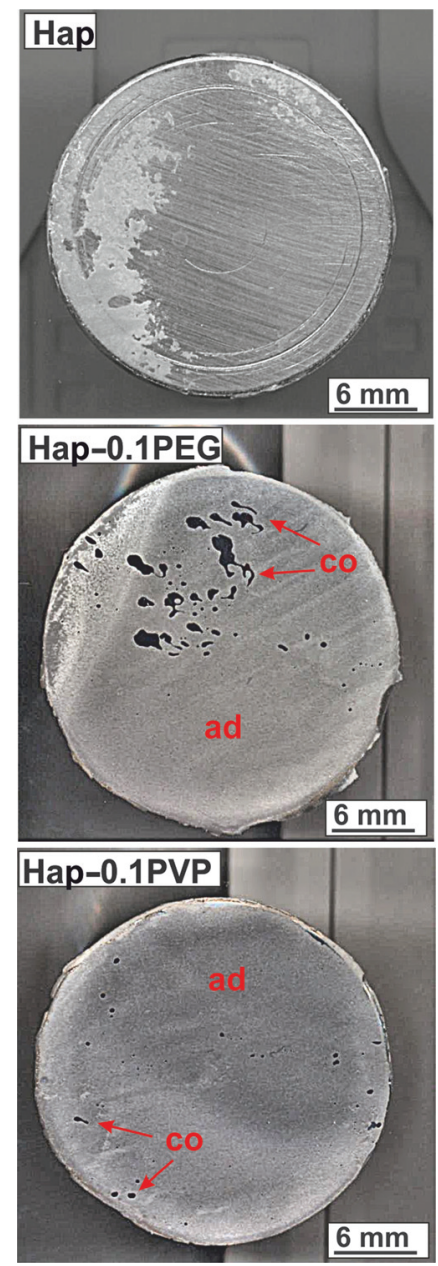

Figure 7. Schematic representation of detached coatings after adhesion strength tests

polymer contained islands found in Hap-0.1PEG coating, which resulted in an increasing cohesive strength inside the coating and tighter mechanical bonding at the coating-substrate interface.

The texture and microstructure analysis of detached composite layers (Figure 8) demonstrate more compact Hap-0.1PVP coating with better separation of Hap particle in agglomerates with more intense contact with relief texture of substrate in comparison with coarse Hap agglomerates clearly separated by polymer enriched regions. This fact caused the decrease in mechanical bonding between substrate and coating because Ti substrate was not perfectly covered with composite. It is clear that physicochemical properties of polymer used in suspension should be optimal from the point of view of disaggregation and proper dispersion of Hap component which was much effective in the ethanolic Hap-0.1PVP suspension.

\section{Conclusions}

In this study, hydroxyapatite coatings were deposited on comercially avalaible $\mathrm{Ti}-6 \mathrm{Al}-4 \mathrm{~V}$ substrates by the low temperature electrostatic spray deposition technique. The aim was to examine the effect of PEG and PVP addition on adhesion strength of thin Hap coatings of $\sim 2-5 \mu \mathrm{m}$ in thickness. The results of fractographic analysis showed that, besides the pure Hap coating, the polymer-doped Hap layers revealed typical adhesion-cohesion failure modes after bonding strength tests. As further shown, the microstructural and EDX map results confirmed the fact that the polymer-doped layers were thoroughly removed from the substrate surfaces after adhesion 

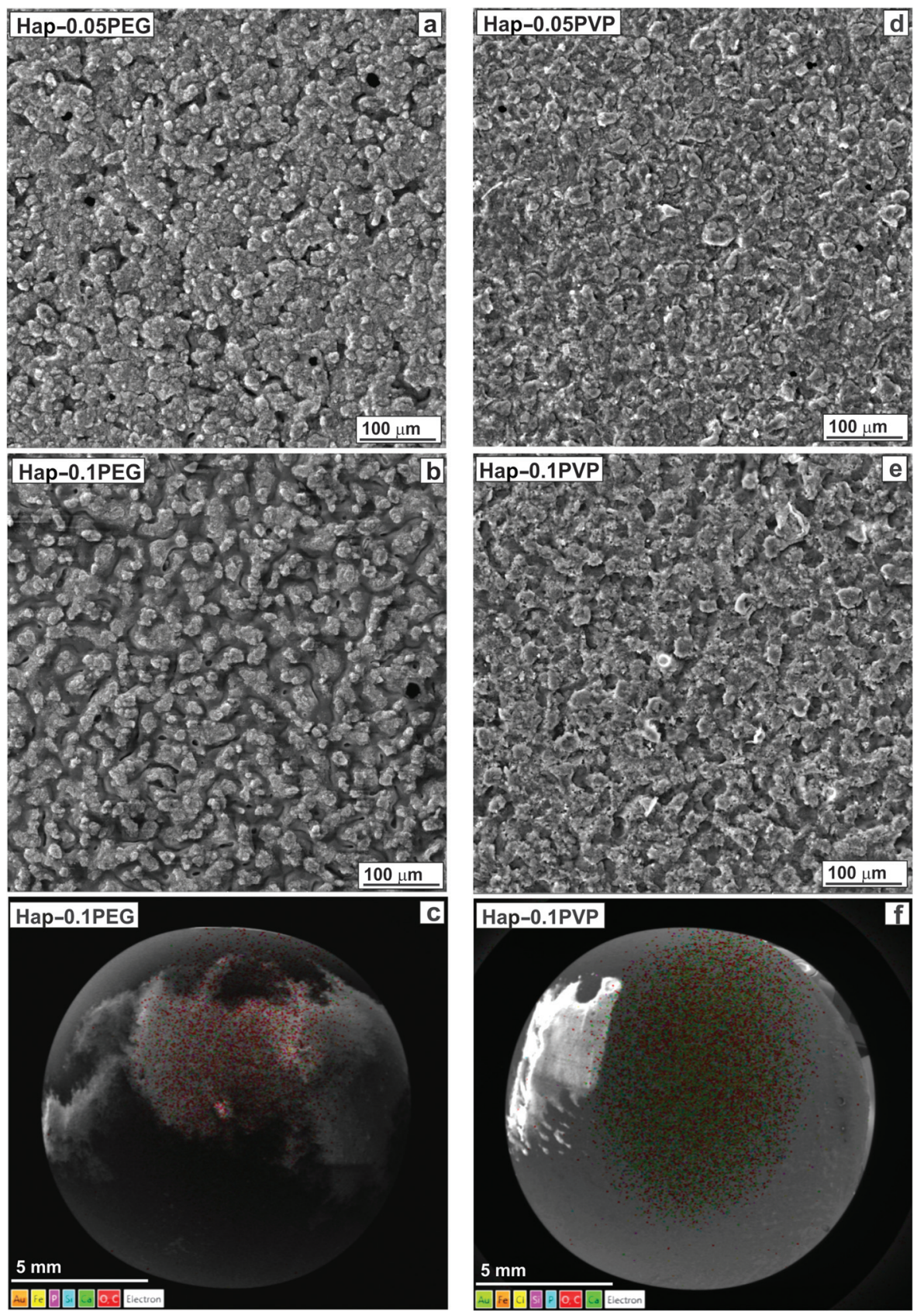

Figure 8. Microstructure and element distribution on the detached coatings after adhesion strength test (a - Hap-0.05PEG; b, c - Hap-0.1PEG) and (d - Hap-0.05PVP; e, f - Hap-0.1PVP)

strength tests. The bonding strengths increase with polymer addition, and the highest value $(8.75 \pm 0.75 \mathrm{MPa})$ was recorded for the Hap-0.1PVP coating. The reason for the rapid increase of adhesion strength was attributed to more uniform, homogeneous, and denser microstructure where the origin pores between the Hap particles were almost completely filled by PVP polymer, which resulted in an increasing cohesive strength inside the coating and tighter mechanical bonding at the coating-substrate interface.

Acknowledgments. This work was supported by the Slovak Grant Agency of the Ministry of Education of the Slovak Republic and the Slovak Academy of Sciences, Project No. 2/0047/17, and within the frame of the project "Advanced implants seeded with stem cells for hard tissues regeneration and reconstruction" which is supported by the Operational Program "Research and Development" financed through European Regional Development Fund. The authors thank Dr. Z.E. Horváth for XRD and L. Illés for SEM/FIB investigations. The work was supported by the European Union Seventh Framework Programme FP7/2007-2013 under grant agreement "HypOrth" No. 602398 and within the frame of the project "Research Centre of Advanced Materials and Technologies for Recent and Future Applications PROMATECH," ITMS 26220220186, supported by the Operational Program "Research and Development" financed through European Regional Development Fund.

Open Access. This is an open-access article distributed under the terms of the Creative Commons Attribution-NonCommercial 4.0 International License (https://creativecommons.org/licenses/ by-nc/4.0/), which permits unrestricted use, distribution, and reproduction in any medium for non-commercial purposes, provided the original author and source are credited, a link to the $\mathrm{CC}$ License is provided, and changes - if any - are indicated. 


\section{References}

1. He, X.; Reichl, F. X.; Wang, Y.; Michalke, B.; Milz, S.; Yang, Y; Stolper, P.; Lindemaier, G. Dent. Mater. J. 2016, 32, 1042-1051. https://doi.org/ 10.1016/j.dental.2016.05.012.

2. Cao, H.; Liu, X. Surf. Coat. Technol. 2013, 233, 57-64. https://doi.org/ 10.1016/j.surfcoat.2013.01.043.

3. Yousefpour, M.; Afshar, A.; Chen, J. Y. Mater. Des. 2007, 28, 2154-2159. https://doi.org/10.1016/j.matdes.2006.06.005.

4. Zhou, H.; Lee, J. Acta Biomater. 2011, 7, 2769-2781. https://doi.org/ 10.1016/j.actbio.2011.03.019.

5. Medvecky, L.; Sopcak, T.; Durisin, J.; Briancin, J. Mater. Lett. 2011, 65 , 3566-3569. https://doi.org/10.1016/j.matlet.2011.07.096.

6. Rao, R. R.; Roopa, H. N.; Kannan, T. S. J. Mater. Sci. Mater. Med. 1997, 8, 511-518. https://doi.org/10.1023/A:1018586412270.

7. Balazsi, C.; Weber, F.; Kover, Z.; Horvath, E.; Nemeth, C. J. Eur. Ceram. Soc. 2007, 27, 1601-1606. https://doi.org/10.1016/j.jeurceramsoc.2006.04.016.

8. Lee, S. W.; Balázsi, C.; Balázsi, K.; Seo, D.; Kim, H. S.; Kim, C. H.; Kim, S. G. J. Tissue Eng. Regen. Med. 2014, 11, 113-120. https://doi.org/10.1007/ s13770-014-0056-1

9. Choi, J. W.; Kong, Y. M.; Kim, H. E. J. Am. Ceram. Soc. 1999, 81 , 1743-1748. https://doi.org/10.1111/j.1151-2916.1998.tb02543.x.

10. Schouten, C.; Meijer, G. J.; Van den Beucken, J. J. J. P.; Leeuwenburgh, S. C. G.; De Jonge, L. T.; Wolke, J. G. C. Acta Biomater. 2010, 6, 2227-2236. https://doi.org/10.1016/j.actbio.2009.11.030

11. Knabe, C.; Howlett, C. R.; Klar, F.; Zreiqat, H. J. Biomed. Mater. Res. A. 2004, 71, 98-107. https://doi.org/10.1002/jbm.a.30130.

12. Mohseni, E.; Zalnezhad, E.; Bushroa, A. R. Int. J. Adhes. Adhes. 2014, 48, 238-257. https://doi.org/10.1016/j.ijadhadh.2013.09.030.

13. Javidi, M.; Javadpour, S.; Bahrololoom, M. E.; Ma, J. Mater. Sci. Eng. C. 2008, 28, 1509-1515. https://doi.org/10.1016/j.msec.2008.04.003.

14. Yang, G. L.; He, F. M.; Hu, J. A.; Wang, X. X.; Zhao, S. F. J. Oral Maxil. Surg. 2010, 68, 420-427. https://doi.org/10.1016/j.joms.2009.09.014. 15. Sridhar, T. M.; Mudali, U. K.; Subbaiyan, M. Corros. Sci. 2003, 45 , 2337-2359. https://doi.org/10.1016/S0010-938X(03)00063-5.

16. Mehboob, H.; Awais, M.; Khalid, H.; Anwar, C. A.; Siddiqi, S. A.; Rehman, I. Biomed. Eng. 2014; 26, 1-8. https://doi.org/10.4015/S1016237214500732.

17. Iqbal, N.; Nazir, R.; Asif, A.; Chaudhry, A. A.; Akram, M.; Fan, G. Y.; Akram, A.; Amin, R.; Park, S. H.; Hussain, R. Curr. App. Phys. 2012, 12, 755-759. https://doi.org/10.1016/j.cap.2011.11.003.
18. Jaworek, A. J. Mater. Sci. 2007, 42, 266-297. https://doi.org/10.1007/ s10853-006-0842-9.

19. Leeuwenburgh, S.; Wolke, J.; Schoonman, J.; Jansen, J. J. Biomed. Mater Res. A. 2003, 66, 330-334. https://doi.org/10.1002/jbm.a.10590

20. Leeuwenburgh, S. C. G.; Wolke, J. G. C.; Schoonman, J.; Jansen, J. A. J. Biomed. Mater. Res. 2005, 74, 275-284. https://doi.org/10.1002/jbm. a.30420.

21. Leeuwenburgh, S. C. G.; Heine, M. C.; Wolke, J. G. C.; Pratsinis, S. E.; Schoonman, J.; Jansen, J. A. Thin Solid Films 2006, 503, 69-78. https://doi.org/ 10.1016/j.tsf.2005.11.116.

22. Panda, R. N.; Hsieh, M. F.; Chung, R. J.; Chin, T. S. J. Phys. Chem. Solids 2003, 64, 193-197. https://doi.or g/10.1016/S0022-3697(02)00257-3.

23. Slosarczyk, A.; Paszkiewicz, Z.; Paluszkiewicz, C. J. Mol. Struct. 2005 744, 657-666. https://doi.org/10.1016/j.molstruc.2004.11.078.

24. Ulian, G.; Valdre, G.; Corno, M.; Ugliengo, P. Am. Mineral. 2015, 98 752-759. https://doi.org/10.2138/am.2013.4315.

25. Venkatasubbu, G. D.; Ramasamy, S.; Avadhani, G. S.; Ramakrishnan, V; Kumar, J. Powder Technol. 2013, 235, 437-442. https://doi.org/10.1016/j. powtec.2012.11.003.

26. Nathanael, A. J.; Seo, Y. H.; Oh, T. H. J. Nanomater. 2015, 6, 1-9. http://dx.doi.org/10.1155/2015/621785.

27. Pereira, E. D.; Cerruti, R.; Fernandes, E.; Peña, L; Saez, V; Pinto, J. C.; Ramón, J. A.; Oliveira, G. E.; de Souza, F. G. Polimeros 2016, 26, 137-143. http://dx.do i.org/10.1590/0104-1428.2323.

28. de Jonge, L. T.; Leeuwenburgh, S. C. G.; van den Beucken, J. J. J. P.; Riet, J.; Daamen, W. F.; Wolke, J. G. C.; Scharnweber, D.; Jansen, J. A Biomaterials 2010, 31, 2461-2469. https://doi.org/10.1016/j.biomaterials.2009.11.114.

29. Zhang, S.; Wang, Y. S.; Zeng, X. T.; Khor, K. A.; Weng, W.; Sun, D. E. Thin Solid Films 2008, 516, 5162-5167. https://doi.org/10.1016/j.tsf.2007.07.063.

30. Yang, C. Y.; Lin, R. M.; Wang, B. C.; Lee, T. M.; Chang, E.; Hang, Y. S.; Chen, P. Q. J. Biomed. Mater. Res. 1997, 37, 335-345. https://doi.org/10.1002/ (SICI)1097-4636(19971205)37:3<335::AID-JBM4>3.0.CO;2-M.

31. Wang, B. C.; Lee, T. M.; Chang, E.; Yang, C. Y. J. Biomed. Mater. Res. 1993, 27, 1315-1327. https://doi.org/10.1002/jbm.820271012.

32. Wang, B. C.; Chang, E.; Yang, C. Y.; Tu, D.; Tasi, C. H. Surf. Coat. Tech. 1993, 58, 107-117. https://doi.org/10.1016/0257-8972(93)90181-M.

33. Munting, E.; Verhelpen, M.; Li, F.; Vincent, A. Contribution of hydroxyapatite coatings to implant fixation, in CRC Handbook of Bioactive Ceramics Vol II, Yamamuro, T.; Hench, L. L.; Wilson, J. eds., CRC Press, Boca Raton, Florida; 1990, pp. 143-148. 